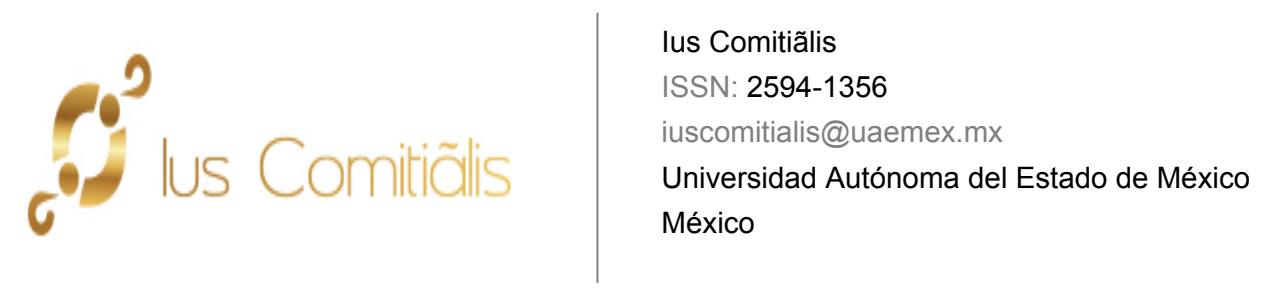

Naime González, Alejandro; Zaragoza Contreras, Laura G.

Inconstitucionalidad de la norma que otorga al Ministerio Público la facultad para solicitar la reducción de las penas en el procedimiento abreviado

lus Comitiãlis, vol. 3, núm. 5, 2020, Enero-Junio, pp. 131-148

Universidad Autónoma del Estado de México

México

DOI: https://doi.org/10.36677/iuscomitialis.v3i5.13722

\title{
Número completo
}

Más información del artículo

Página de la revista en redalyc.org 
Inconstitucionalidad de la norma que otorga al Ministerio

Público la facultad para solicitar la reducción de las penas

en el Procedimiento Abreviado

Unconstitutionality of the standard that gives to the Public

Ministry the faculty to request the reduction of the penalties in the Aborved Procedure

\section{(c) (1) (2) (2)}

Esta obra está bajo licencia Creative Commons Attribution-NonCommercial-ShareAlike $\quad 4.0$ International (CC BY-NC-SA 4.0)

Resumen En el presente estudio se revisa y se evidencia que, en el Código Nacional de Procedimientos Penales, al reglamentar la punición aplicable en el procedimiento abreviado, se violentan derechos humanos al transferir al Ministerio Público una atribución exclusiva del Poder Judicial lo que, además de inconstitucional, limita el acceso a la justicia, rompe el principio de equilibrio procesal entre las partes y favorece la corrupción y la impunidad.

Palabras clave Reglas para aplicar penas en el procedimiento abreviado, acceso a la justicia, igualdad de las partes, reducción de penas.

Abstract The aim of this paper is to review and show evidence in regards to current regulation in punishing the abbreviated procedure stated by National Code of Criminal Procedures. Human rights are violated when transferring to the Public Ministry an exclusive function of the Judicial System which, in addition to unconstitutional, it limits access to justice, breaks the principle of procedural balance between the parties and favors corruption and impunity.

Key words Rules for applying penalties in the abbreviated procedure, access to justice, equality of the parties, reduction of penalties.

\footnotetext{
*Doctor en Derecho por la Facultad de Derecho de la Universidad Autónoma del Estado de México, México. Profesor de la Escuela Judicial del Poder Judicial del Estado de México, de las materias Teoría de la Pena y Ejecución de Sentencias. Magistrado por Oposición en Retiro, del Poder Judicial del Estado de México y actualmente Consultor Jurídico en "Consultoría Jurídica Naime-Naime". ORCID: https://orcid.org/0000-0003-2765-4955. Correo electrónico: alejandronaime@hotmail.com **Doctora en Ciencias Sociales y Políticas por la Universidad Iberoamericana.

Profesora Investigadora de laUniversidad Nacional Autonoma de Mexico y de la Universidad Autonoma del Estado de Mexico, Mexico.

ORCID: https://orcid.org/0000-0001-7703-4303.

Correo electrónico: laurazaragozacontreras@live.com.mwx
} 


\section{INTRODUCCIÓN}

El sistema de enjuiciamiento penal en México se refiere a una institución que encuentra su sustento en el artículo 20 Apartado A de la Constitución Política de los Estados Unidos Mexicanos (reforma de 2008), entraña múltiples procedimientos que se reglamentan, principalmente en el Código Nacional de Procedimientos Penales (Diario Oficial de la Federación, México, 5 de marzo de 2014), y que deben examinarse de manera cuidadosa para identificar los casos en los que haya omisiones, defectos o excesos, para propiciar los ajustes necesarios y así lograr el verdadero acceso a la justicia por parte de los protagonistas del procedimiento penal: la víctima, el ofendido y el imputado.

Una de las figuras destacadas del sistema penal acusatorio, es la opción para terminar en forma anticipada el procedimiento, bajo determinados requisitos, lo que está encaminado principalmente a la pronta administración de justicia, traducida en el esclarecimiento de los hechos, la protección de los inocentes, evitar la impunidad y que se reparen los daños causados, tal y como se señala en el artículo 20 apartado A del texto constitucional y, también evitar la saturación innecesaria de juicios en los tribunales. Es un mecanismo de justicia concertado entre las partes que debe de llevar a la pronta solución del conflicto penal.

Pero a pesar de ser una institución aparentemente bondadosa, se considera que su reglamentación contiene elementos que, eventualmente pueden lesionar derechos humanos, provocando además, la invasión de la competencia constitucional del Poder Judicial por parte de las fiscalías General de la República y las de los estados de la federación, con lo que posiblemente se incumpla su función social y procesal y con ello, el sistema penal pudiera estar en medio de una crisis que debe ser objeto de atención inmediata por los especialistas y los investigadores, para llamar pronto la atención de los legisladores y no dejar que todo sea resuelto o regulado a través de la jurisprudencia de la Suprema Corte de Justicia de la Nación.

\section{LA TERMINACIÓN ANTICIPADA DEL PROCEDIMIENTO PENAL, COMO UNA FORMA DE ACCESO A LA JUSTICIA EN MÉXICO}

La reforma constitucional al sistema de enjuiciamiento penal en México, publicada en el Diario Oficial de la Federación el 18 de junio de 2008, constituye un hito que modifica el paradigma del deteriorado sistema penal inquisitivo, dando lugar a la estructura del procedimiento de naturaleza acusatorio, el cual, dentro de sus principales características se encuentran: 
a. La separación de funciones entre el órgano que acusa y el que resuelve.

b. La igualdad procesal, donde el imputado se defiende ante un juez imparcial de las acusaciones del Ministerio Público.

c. Las pretensiones, argumentaciones y pruebas en el desarrollo del proceso se deben plantear, introducir y desahogar en forma oral, bajo los principios de inmediación y contradicción.

d. La presunción de inocencia se establece de manera expresa (López en Pereznieto, 2019, p. 28).

Se trata de una reforma integral, ya que abarca toda la estructura del procedimiento penal que ahora opera en México. En particular, desde el punto de vista del acceso a la justicia, es necesario realizar algunas consideraciones sobre uno de los temas novedosos del sistema, relativo a su forma de terminación anticipada, a través del Procedimiento Abreviado, pero en relación con la injerencia que el legislador le da al órgano acusador en su tramitación y las implicaciones que ello tiene respecto al principio de igualdad o equilibrio de las partes y frente a las atribuciones constitucionales exclusivas de los poderes judiciales.

El artículo 20 apartado A de la Constitución Política de los Estados Unidos Mexicanos (CPEUM, 1917), establece como uno de los principios generales del proceso penal acusatorio y oral:

VII. Una vez iniciado el proceso penal, siempre y cuando no exista oposición del inculpado, se podrá decretar su terminación anticipada en los supuestos y bajo las modalidades que determine la ley. Si el imputado reconoce ante la autoridad judicial, voluntariamente y con conocimiento de las consecuencias, su participación en el delito y existen medios de convicción suficientes para corroborar la imputación, el juez citará a audiencia de sentencia. La ley establecerá los beneficios que podrán otorgarse al inculpado cuando acepte su responsabilidad.

Una de las finalidades de esta reforma es evitar llevar a juicio todos los asuntos que se judicialicen, precisamente, en aquellos casos en donde exista aceptación del hecho delictuoso por parte del imputado y obren datos de prueba que confirmen la imputación de que es objeto. Este mecanismo supone erradicar el desgaste innecesario de la maquinaria jurisdiccional, evitando enjuiciar los asuntos que pueden encontrar una conclusión anticipada y en donde el investigado o acusado, a cambio de reconocer su intervención en el hecho, reciba un beneficio desde el punto de vista de la punición privativa de libertad y pecuniaria que la ley penal asigne al hecho delictuoso por el cual ha sido vinculado a proceso.

A través del procedimiento abreviado, según el derecho humano establecido en el texto constitucional, los gobernados tienen acceso a la justicia, pues una vez cometido un hecho señalado por la ley como delito y existiendo quien acepte la responsabilidad de su comisión, el Estado impondrá las penas que la ley señale para ese hecho y se garantiza el pago de la reparación del daño, cuando así proceda. Entonces, la víctima u ofendido, verá reparado el daño que se le ha causado y el sentenciado obtendrá el beneficio de una pena reducida, iniciando así su proceso de reinserción social. 


\section{EL PROPÓSITO CONSTITUCIONAL DE LA PENA DE PRISIÓN}

Desde 1917, en el texto constitucional, la finalidad de la pena ha transitado por tres etapas:

a) Regeneración;

b) Readaptación; y

c) Reinserción.

La primera etapa tuvo una vigencia de 48 años: de 1917 a 1965, y el texto constitucional establecía:

Art. 18. Sólo por delito que merezca pena corporal habrá lugar a prisión preventiva. El lugar de ésta será distinto y estará completamente separado del que se destinare para la extinción de las penas.

Los gobiernos de la Federación y de los Estados organizarán, en sus respectivos territorios, el sistema penal -colonias, penitenciarías o presidiossobre la base del trabajo como medio de regeneración.

Este texto podría calificarse como una regulación incipiente respecto del fin de la pena, pero debe recordarse que las condiciones criminógenas de la época en nuestro país eran totalmente diferentes a las que privan actualmente. El constituyente determinó que el trabajo era el medio para lograr la regeneración social.

Fue una etapa en la cual, el sistema penal revelaba abandono y el tema de las prisiones y las cárceles así lo demuestran ya que, no constituía una verdadera política criminal. Era prácticamente el encierro por el encierro, así como el aislamiento, aunque superaba de alguna forma las condiciones carcelarias del siglo xIX que eran verdaderamente deplorables.

El tema del sistema penitenciario se convirtió en parte de la política criminal del Estado mexicano, a partir de la reforma constitucional publicada en el Diario Oficial de la Federación, el 23 de febrero de 1965, en el que se inicia la segunda etapa por la que transita la finalidad de la pena de prisión, - de la regeneración a la readaptación social - y, donde el sistema de ejecución de ésta, cobra relevancia y se sientan las bases para una verdadera transformación integral en la materia, de acuerdo con las condiciones de la época.

Y, el nuevo texto constitucional señaló:

ARTíCULO 18. Sólo por delito que merezca pena corporal habrá lugar a prisión preventiva. El sitio de ésta será distinto del que se destinare para la extinción de las penas y estarán completamente separados.

Los Gobiernos de la Federación y de los Estados organizarán el sistema penal, en sus respectivas jurisdicciones, sobre la base del trabajo, la capacitación para el mismo y la educación como medios para la readaptación social del delincuente. Las mujeres compurgarán sus penas en lugares separados de los destinados a los hombres para tal efecto.

Los Gobernadores de los Estados, sujetándose a lo que establezcan las leyes locales respectivas, podrán celebrar con la Federación convenios de carácter general, para que los reos sentenciados por delitos del orden común extingan su condena en establecimientos dependientes del Ejecutivo Federal. 
La Federación y los Gobiernos de los Estados establecerán instituciones especiales para el tratamiento de menores infractores.

La idea de Readaptación Social, era desde luego ajustar la conducta del sujeto a la norma social prevaleciente en la época, sin aspirar sólo a la regeneración del individuo; se trató de un nuevo concepto, más ambicioso que la mera readaptación social. Incluyó como medio, además del trabajo, la capacitación para éste y la educación; se pretendía que el infractor volviera a observar el comportamiento que regularmente siguen y aprueban los integrantes de la sociedad a la que pertenecen. La intención era lograr ajustar el comportamiento del delincuente con la cultura prevaleciente. Este propósito era colocar al delincuente en condiciones de no volver a delinquir, dándole los elementos para valorar, regular y orientar su conducta, sin privarlo de su capacidad de decisión, ya que ésta le daba sentido moral y valor jurídico a su comportamiento. Esta etapa tuvo una vigencia de aproximadamente 43 años.

Finalmente, la tercera etapa inició con la reforma al sistema de enjuiciamiento penal vigente, donde se modificó el objetivo de la pena de prisión y, a partir del 10 de junio de 2011, en la primera parte del párrafo segundo del artículo 18 constitucional se determina que:

El sistema penitenciario se organizará sobre la base del respeto a los derechos humanos, el trabajo, la capacitación para el mismo, la educación, la salud y el deporte como medios para lograr la reinserción del sentenciado a la sociedad y procurar que no vuelva a delinquir, observando los beneficios que para él prevé la ley. Las mujeres compurgarán sus penas en lugares separados de los destinados a los hombres para tal efecto.

El dictamen de la reforma consideró a la expresión Readaptación Social, como un término inadecuado para nombrar el momento en el que los sentenciados terminan su condena y se insertan nuevamente en su entorno social.

Con la reforma se omitió considerar que el concepto readaptación no se refiere al momento en que concluye la ejecución de la sentencia, este abarca desde que el infractor ingresa al centro de reclusión y hasta el tratamiento en libertad después de la ejecución material de la pena. Incluso ahora la Ley Nacional de Ejecución Penal (Diario Oficial de la Federación, México, 16 de junio de 2016), lo establece como un principio rector del sistema penitenciario:

"Reinserción Social: Restitución del pleno ejercicio de las libertades tras el cumplimiento de una sanción o medida ejecutada con respeto a los derechos humanos".

Aun cuando el término Reinserción Social en este apartado pudiera considerarse que se reduce a devolver al condenado el goce de los derechos que le fueron suspendidos con motivo de la prisión al cumplir ésta, la interpretación realizada por la Comisión Nacional de los Derechos Humanos (CNDH) en "Derechos Humanos de las Personas en Reclusión Penitenciaria, Marco normativo nacional e internacional del sistema penitenciario" (2019, pp. 5-6) lo aclara al señalar que es importante considerar lo previsto en el artículo 18 constitucional respecto de la organización del sistema penitenciario "sobre la base del respeto a los derechos humanos". Es decir, que salvo aquellos derechos que le están legalmente restringidos, toda persona en los Estados Unidos Mexicanos, aun estando en reclusión penitenciaria gozará de los derechos humanos reconocidos en la Constitución y en los tratados internacionales de los que el Estado mexicano sea parte, así como de las garantías para su protección. 
Cuando se aborda el tema de los derechos de las personas en reclusión penitenciaria, es importante reconocer que toda persona que se encuentra privada de la libertad es titular de los mismos derechos que le son reconocidos a los demás miembros de la sociedad, sin perjuicio de las restricciones que se harán a ciertos derechos durante el tiempo que se encuentre en reclusión.

Sin embargo, gozan del respeto a la dignidad inherente de todos los seres humanos y, por ende, la privación de la libertad derivada de una medida cautelar o de condena de prisión no puede significar, en ningún caso, la violación de otros derechos fundamentales.

Cuando se priva de la libertad a una persona, ya sea en prisión preventiva como medida cautelar o compurgando una sentencia, esta reclusión debe cumplir primordialmente dos objetivos: proteger a la sociedad del riesgo que la persona pueda representar si se encuentra en libertad y que no vuelva a delinquir al reinsertarla de manera efectiva a la sociedad.

Aunque una realidad innegable es que la crisis que prevalece desde hace años en el sistema penitenciario actual, provocada por el crecimiento irrefrenable de la criminalidad sobre todo organizada, la sobrepoblación de los centros de reclusión por las desorbitantes penalidades que pueden imponerse con algunos códigos sustantivos, la reducción de los beneficios preliberacionales y de libertad anticipada, el auto gobierno, la corrupción y la impunidad, no permiten que se logre consumar el nuevo propósito de la reinserción social, así como tampoco permitieron el de la readaptación social en sus últimos años de vigencia.

Lo cierto es que hay aparentemente un nuevo paradigma constitucional en la finalidad de la pena de prisión, y será un tema a efectivizarse eventualmente a través de una política criminal adecuada y homogénea en la Federación, los Estados y la Ciudad de México y, sobre todo, un tema de política pública de esos niveles de gobierno, en materia social, bienestar, educación y seguridad pública.

\section{EL PROCEDIMIENTO ABREVIADO EN EL CÓDIGO NACIONAL DE PRO- CEDIMIENTOS PENALES Y LAS FACULTADES SUPRA - CONSTITUCIO- NALES DEL MINISTERIO PÚBLICO}

El Código Nacional de Procedimientos Penales (CNPP), establece en el Libro Segundo. Título I, Capítulo I:

Artículo 185. Formas de terminación anticipada del proceso.

El procedimiento abreviado será considerado una forma de terminación anticipada del proceso.

Y en el capítulo IV, de los artículos 201 al 207, se regula todo lo relativo al procedimiento abreviado, de donde se destacan los siguientes aspectos:

- Solo se apertura a petición del Ministerio Público, pero el Juez de Control es quien resuelve si se reúnen los requisitos legales para ello;

- Procede una vez dictado el auto de vinculación a proceso y hasta antes de emitirse el auto de apertura a juicio oral;

- La acusación del Ministerio Público debe ser específica para el procedimiento abreviado y, los datos de prueba que la sustenten deben ser suficientes para confirmar la imputación que se ha realizado al investigado y 
especificar: los hechos que se le atribuyen, su clasificación jurídica, su grado de intervención y el pedimento de la reducción de las penas mínimas;

- Que no haya oposición de la víctima u ofendido, la que solo será vinculante para el juez cuando se acredite que la reparación del daño no está garantizada;

- Que el imputado acepte estar debidamente informado del contenido y alcance del procedimiento, renuncie al enjuiciamiento oral, consienta ser juzgado en procedimiento abreviado con los datos de prueba incorporados por el Ministerio Público y reconozca su responsabilidad en el hecho que se le atribuye.

Y, una vez aprobada la tramitación del procedimiento abreviado, el juez impondrá la pena mínima que corresponda al delito por el que fue acusado y el Ministerio Público podrá pedir la reducción de la punición corporal y pecuniaria impuestas (desde luego, no se incluye a la reparación del daño), en principio, de acuerdo con las siguientes reglas procesales, en términos de los establecido en el artículo 202 del cNPP:

a) Podrá pedir la reducción de hasta la mitad de la pena mínima, en el caso de que se trate de un delito doloso y el imputado no haya sido condenado previamente por delito doloso y el término medio aritmético de la pena por el delito que se le acusa, incluyendo sus modificativas, no exceda de 5 años.

b) Podrá pedir la reducción de hasta las dos terceras partes de la pena mínima, cuando se trate de un delito culposo, e igualmente el imputado no haya sido condenado previamente por delito doloso y el término medio aritmético de la pena por el delito que se le acusa no exceda de 5 años incluyendo sus modificativas. c) De existir condena previa por delito doloso y/o exceder del término medio aritmético de 5 años la pena por el delito por el que se formuló acusación, el ministerio público podrá pedir la reducción de hasta un tercio de la pena mínima, si se trata de un delito doloso.

d) Y de haber sentencia condenatoria anterior por delito doloso y/o exceder del término medio aritmético de 5 años la pena por el delito por el que se plantea acusación, el fiscal podrá pedir la reducción de hasta la mitad de la pena mínima, si se trata de un delito culposo (las cursivas son nuestras).

Con esta regulación, el Ministerio Público adquiere una facultad punitiva doblemente potestativa, ya que, en principio, tiene la atribución optativa de solicitar la reducción de las penas mínimas a imponer al acusado que admita ser sujeto del procedimiento abreviado y por otro, tiene la facultad de graduar el monto de la reducción, ya que la ley le fija el máximo en cada caso, pero no establece el mínimo a conceder, lo que, permite un margen de maniobra importante. Esta atribución se regula, de conformidad con el último párrafo del artículo 202 del CNPP, a través del Acuerdo que al efecto emitan los respectivos Procuradores (ahora Fiscales) Federal y de las respectivas entidades federativas.

Entonces, el legislador, a través del cNPP deja en manos del Ministerio Público dos atribuciones que resultan constitucionalmente cuestionables, ya que, por un lado, se afecta el principio de igualdad procesal entre las partes establecido en el artículo 11 del CNPP, tal como ya se ha analizado en diverso estudio (Naime y Zaragoza, 2019) y, por otro lado, invade la esfera de competencia de la autoridad judicial, produciendo desafortunadas consecuencias.

En relación con el segundo de los planteamientos, debe recordarse que el artículo 21 párrafo tercero de la CPEUM establece: 
"La imposición de las penas, su modificación y duración son propias y exclusivas de la autoridad judicial".

El tema del monopolio de la imposición de las sanciones en el procedimiento penal, no tendría motivo alguno de discusión, ya que, en la trayectoria constitucional del Estado mexicano, bajo el principio de la separación de poderes, ha sido una facultad exclusiva del Poder Judicial. Pero ahora, con la reforma constitucional al sistema de enjuiciamiento penal de 2008, el legislador le ha compartido esa facultad al Ministerio Público dentro del procedimiento abreviado.

Esto, desde luego trastoca al sistema jurídico constitucional, al otorgar facultades al Ministerio Público, las cuales rebasan los límites establecidos en la CPEUM, lo que además constituye una herramienta colocada en manos inadecuadas y desafortunadamente limita el acceso a la justicia por parte de los imputados y fomenta las prácticas de corrupción y la impunidad.

Como ya se ha advertido, en los párrafos tercero y cuarto del artículo 202 del CNPP, se establece que la punición aplicable por el juez a los imputados que acepten ser sujetos de procedimiento abreviado, debe ser la mínima y que el Ministerio Público podrá pedir su reducción en las condiciones ahí incluidas y el párrafo final del propio precepto, determina que el mismo Ministerio Público debe atender el acuerdo que sobre ello emita el Procurador, ahora Fiscal.

Así, el CNPP establece los límites máximos de reducción de las penas que podrá autorizar el Ministerio Público se realicen a penas las mínimas que imponga el órgano jurisdiccional y en los delitos donde aplique. Los procuradores y los ahora fiscales General de la República y Generales de Justicia de cada una de las entidades federativas, han emitido los acuerdos correspondientes para reglamentar esta potestad ministerial. Se han seleccionado dos casos para su revisión:

En el caso de la Procuraduría General de la República (hoy Fiscalía General de la República), el entonces titular emitió el acuerdo A/017/2015, el 30 de enero de 2015, publicado en el Diario Oficial de la Federación el 23 de febrero de 2015. Y en el caso del Estado de México, el Fiscal General de Justicia del Estado, incluyó los lineamientos para solicitar la reducción de las penas dentro del procedimiento abreviado, en el documento denominado Protocolo General de Investigación y Persecución del Delito, autorizado por acuerdo, inicialmente denominado 06/ 2016 publicado en el periódico Oficial Gaceta del Gobierno del Estado de México el 18 de mayo de 2016, pero por fe de erratas publicada en el mismo periódico el 10 de junio de 2016, se denominó Acuerdo 10/2016.

Por razones desconocidas, es imposible acceder libremente a este protocolo, porque al parecer es de uso exclusivo de los servidores públicos de la Fiscalía General de Justicia del Estado de México, aun cuando en el caso de los lineamientos que debe observar el Ministerio Público para solicitar la reducción de las penas en el procedimiento abreviado, deben ser del conocimiento general. Sin embargo, a través de la solicitud de información pública número 00540/FGJ/IP/2017, realizada ante el Instituto de Transparencia, Acceso a la Información Pública y Protección de Datos Personales del Estado de México y Municipios, se obtuvo la información por parte del Oficial Mayor y Jefe de la Unidad de Transparencia de la Fiscalía General de Justicia del Estado de México, al rendir el Informe de Justificación, dentro del recurso de revisión que se interpuso en contra de la respuesta inicial que emitió, en razón de no proporcionar la información solicitada en primera instancia. Dicho medio de impugnación se registró con el folio número 02591/INFOEM/IP/RR/2017.

Debe precisarse que la Conferencia Nacional de Procuración de Justicia, en su XXXIII Asamblea Plenaria, a través del Acuerdo CNPJ/XXXIII/12/2015, del 19 de noviembre de 2015, emitió los Lineamientos por los que se establecen los criterios ge- 
nerales y el procedimiento para la aplicación de los criterios de oportunidad y de la determinación de la pena que el ministerio público solicitará al juez de control en la aplicación del procedimiento abreviado, consultables en la página electrónica de la Normateca de la Procuraduría General de la República (hoy Fiscalía General de la República, cuyo extracto fue publicado en el Diario Oficial de la Federación del 9 de febrero de 2016, donde en el Capítulo Tercero, en los lineamientos Décimo Cuarto y Décimo Quinto se proponen, como fórmula para la reducción de las penas, por un lado, la gravedad de la conducta, el grado de culpabilidad del acusado y en su caso, los usos y costumbres, cuando el acusado sea parte de un grupo étnico o pueblo indígena y por otro lado, para graduar la proporción de reducción, los lineamientos sugieren: menor reducción si el imputado ha sido condenado por delito doloso en cualquier fuero; menor reducción si el delito amerita prisión preventiva oficiosa; mayor reducción si el imputado aportó información que ayudó eficazmente a evitar la comisión de otro delito o en la investigación de otros imputados o delitos (las cursivas son nuestras).

Los lineamientos fueron adoptados por diversas procuradurías o fiscalías de manera literal o casi literal para emitir sus respectivos acuerdos; en algunas entidades hay ligeras variantes, pero en esencia se observa que sirvieron de modelo para la emisión de sus acuerdos, salvo el caso de la entonces Procuraduría General de la República, porque su titular emitió el acuerdo relativo, antes de que se expidieran los lineamientos, pues data del 30 de enero de 2015 y fue publicado el 23 de febrero siguiente.

Es un caso notoriamente peculiar, porque los criterios que este acuerdo establece para la reducción de las penas, son precisamente los mismos que se adoptaron por la Conferencia Nacional de Procuración de Justicia, es decir, este acuerdo fue en realidad el modelo a seguir por la agrupación de titulares de las procuradurías y fiscalías del país y adoptado por la mayoría de los mismos para emitir los suyos, pero el Acuerdo del Ministerio Público Federal presenta una variante que no se incluyó en los lineamientos adoptados por la Conferencia Nacional y que es materia de revisión en párrafos posteriores.

ACUERDO DE LA FISCALÍA GENERAL DE LA REPÚBLICA

El acuerdo A/017/15, que emitió el entonces Procurador General de la República, establece los criterios generales y el procedimiento a observar por los Agentes del Ministerio Público Federal para solicitar la pena (sic) en el procedimiento abreviado.

Este acuerdo se integra por diez incisos e inicialmente, en el segundo y tercero, se establece, en concordancia con lo dispuesto por los párrafos tercero y cuarto del artículo 202 del CNPP, que cuando el acusado no haya sido sancionado previamente por delito doloso y el término medio aritmético del delito por el que se le acusa, no excede de 5 años, incluidas sus circunstancias modificativas, el Ministerio Público Federal podrá pedir la reducción dentro de los siguientes márgenes de punibilidad:

a) Desde un día de la pena máxima, hasta dos terceras partes de la pena mínima que corresponda al delito, cuando se trate de un delito culposo;

b) O desde un día de la pena máxima hasta una mitad de la pena mínima, cuando se trate de delitos dolosos (las cursivas son nuestras).

Y, que fuera de los casos anteriores, el Ministerio Público Federal podrá pedir la reducción dentro de los siguientes parámetros:

a) Desde un día de la pena máxima, hasta la mitad de la pena mínima que le corresponda al delito, cuando se trate de uno de naturaleza culposa; 
b) $\mathrm{O}$, desde un día de la pena máxima, hasta un tercio de la pena mínima que le corresponda al delito, cuando se trate de uno de naturaleza dolosa (las cursivas son nuestras).

Entonces, estos dos incisos concretan los parámetros de reducción de las penas mínimas que puede solicitar el Ministerio Público, acorde con el cNPP, estableciendo el mínimo de reducción que pueden peticionar, pues el máximo ya está establecido en el ese ordenamiento.

Debe señalarse que resulta extraña la expresión desde un día de la pena máxi$m a$, porque es una frase que no tiene sentido. La palabra máxima desde luego se refiere al límite máximo de una pena señalada para un delito en particular, ya que las legislaciones sustantivas penales, en cada delito por regla general establecen un límite mínimo y un límite máximo de pena a imponer (prisión, multa, suspensión de derechos, etc.), dentro de los cuales, el órgano jurisdiccional habrá de establecer la penalidad concreta a imponer, según el grado de punición en que haya ubicado a delincuente. Por esa razón, se considera que la expresión desde un día de la pena máxima resulta desafortunada, ya que ésta, se forma por una sola cantidad concreta que no tiene dentro de sí misma otros parámetros.

Por ejemplo: en el Código Penal para el Estado de México, el artículo 242, fracción I, párrafo primero, establece que "Al responsable del delito de homicidio simple, se le impondrán de diez a quince años de prisión y de doscientos cincuenta a trescientos setenta y cinco días multa (...)". Entonces, si así se establecen las penas máximas en todos los delitos que se describen en las legislaciones sustantivas penales en México, es inadecuada la expresión un día de la pena máxima porque es algo inexistente. Bastaba señalar que la porción de reducción de la pena que determine el Ministerio Público será como mínimo de un día y como máximo los rangos señalados por el CNPP (artículo 202 párrafos tercero y cuarto).

Así, este Acuerdo determina el mínimo de la reducción de penas que puede conceder el Ministerio Público, frente a los máximos que establece el cNPP como se ha señalado.

Luego, en el cuarto inciso establece tres reglas para determinar la punibilidad que podrá solicitar se le imponga al acusado que acepte ser susceptible de ser juzgado en un procedimiento abreviado y son:

I. La gravedad de la conducta típica y antijurídica, con base en el valor del bien jurídico, el grado de afectación, los medios empleados, las circunstancias de tiempo, modo, lugar u ocasión del hecho, así como por la forma de intervención del imputado:

II. El grado de culpabilidad, con base en las circunstancias y características del hecho, la posibilidad de comportarse de manera distinta y de haber respetado la norma quebrantada, así como los motivos que lo llevaron a cometerlo; la edad, el nivel educativo, sus costumbres, las condiciones sociales y culturales; el vínculo de parentesco, relación o amistad que guarde con la víctima u ofendido y demás circunstancias especiales del imputado, víctima u ofendido, y

III. Los usos y costumbres, en caso de que el imputado pertenezca a un grupo étnico o pueblo indígena.

Desde luego, estos son elementos que el titular de la entonces Procuraduría General de la República, tomó del propio CNPP, precisamente del artículo 410, en el que 
se establecen los lineamientos que debe observar el juez, al momento de realizar la individualización de las penas o medidas de seguridad, a quienes hayan encontrado responsables de la comisión de un delito. Tal dispositivo establece:

Artículo 410. Criterios para la individualización de la sanción penal o medida de seguridad

El Tribunal de enjuiciamiento al individualizar las penas o medidas de seguridad aplicables deberá tomar en consideración lo siguiente:

Dentro de los márgenes de punibilidad establecidos en las leyes penales, el Tribunal de enjuiciamiento individualizará la sanción tomando como referencia la gravedad de la conducta típica y antijurídica, así como el grado de culpabilidad del sentenciado. Las medidas de seguridad no accesorias a la pena y las consecuencias jurídicas aplicables a las personas morales, serán individualizadas tomando solamente en consideración la gravedad de la conducta típica y antijurídica.

La gravedad de la conducta típica y antijurídica estará determinada por el valor del bien jurídico, su grado de afectación, la naturaleza dolosa o culposa de la conducta, los medios empleados, las circunstancias de tiempo, modo, lugar u ocasión del hecho, así como por la forma de intervención del sentenciado.

El grado de culpabilidad estará determinado por el juicio de reproche, según el sentenciado haya tenido, bajo las circunstancias y características del hecho, la posibilidad concreta de comportarse de distinta manera y de respetar la norma jurídica quebrantada. Si en un mismo hecho intervinieron varias personas, cada una de ellas será sancionada de acuerdo con el grado de su propia culpabilidad.

Para determinar el grado de culpabilidad también se tomarán en cuenta los motivos que impulsaron la conducta del sentenciado, las condiciones fisiológicas y psicológicas específicas en que se encontraba en el momento de la comisión del hecho, la edad, el nivel educativo, las costumbres, las condiciones sociales y culturales, así como los vínculos de parentesco, amistad o relación que guarde con la víctima u ofendido. Igualmente se tomarán en cuenta las demás circunstancias especiales del sentenciado, víctima u ofendido, siempre que resulten relevantes para la individualización de la sanción.

Se podrán tomar en consideración los dictámenes periciales y otros medios de prueba para los fines señalados en el presente artículo.

Cuando el sentenciado pertenezca a un grupo étnico o pueblo indígena se tomarán en cuenta, además de los aspectos anteriores, sus usos y costumbres.

En caso de concurso real se impondrá la sanción del delito más grave, la cual podrá aumentarse con las penas que la ley contempla para cada uno de los delitos restantes, sin que exceda de los máximos señalados en la ley penal aplicable. En caso de concurso ideal, se impondrán las sanciones correspondientes al delito que merezca la mayor penalidad, las cuales podrán aumentarse sin rebasar la mitad del máximo de la duración de las penas correspondientes de los delitos restantes, siempre que las sanciones aplicables sean de la misma naturaleza; cuando sean 
de diversa naturaleza, podrán imponerse las consecuencias jurídicas señaladas para los restantes delitos. No habrá concurso cuando las conductas constituyan un delito continuado; sin embargo, en estos casos se aumentará la sanción penal hasta en una mitad de la correspondiente al máximo del delito cometido.

El aumento o la disminución de la pena, fundados en las relaciones personales o en las circunstancias subjetivas del autor de un delito, no serán aplicables a los demás sujetos que intervinieron en aquél. Sí serán aplicables las que se fundamenten en circunstancias objetivas, siempre que los demás sujetos tengan conocimiento de ellas.

Lo anterior revela un ejercicio de cuantificación del monto de la reducción de las penas que puede conceder el Ministerio Público dentro del procedimiento abreviado, tomado de una de las funciones sustantivas del órgano jurisdiccional. Lo que resulta contradictorio, porque finalmente no es el único parámetro que el Ministerio Público habrá de observar para determinar la reducción de la pena mínima, -como enseguida se señala-, lo que además convierte la facultad potestativa del órgano investigador, en un tema por demás complejo y confuso.

En el quinto inciso, el acuerdo del entonces Procurador General de la República establece que, para autorizar la reducción de las penas, se debe considerar:

a) Menor reducción si el imputado ha sido condenado por un delito doloso en cualquier fuero.

b)Menor reducción si el delito amerita prisión preventiva oficiosa; y

c) Mayor reducción si el imputado aportó información para evitar la comisión de nuevos delitos o en la investigación de otros imputados o delitos.

d) Mayor reducción si la apertura del procedimiento abreviado se concretó con más cercanía al dictado del auto de vinculación a proceso y menor reducción si fue con mayor proximidad al auto de apertura a juicio oral (las cursivas son nuestras).

En los incisos, del sexto al décimo del Acuerdo en comento, se establecen los lineamientos del trámite administrativo que debe observarse para la autorización y concesión de la reducción de la pena mínima en el procedimiento abreviado.

Como se puede advertir, el acuerdo es complejo, porque contiene una multiplicidad de lineamientos que, por un lado le hacen actuar bajo criterios legales exclusivos de la autoridad jurisdiccional en el procedimiento de individualización de sanciones y por el otro, bajo parámetros subjetivos que chocan totalmente con los primeros, establecen el mecanismo para solicitar la reducción de sanciones, lo que genera - entre otras -, inseguridad jurídica para los imputados que aspiren a la terminación anticipada del procedimiento.

ACUERDO DE LA FISCALÍA GENERAL DE JUSTICIA DEL ESTADO DE MÉXICO

Por lo que hace al caso de la Fiscalía General de Justicia del Estado de México, como se señaló en párrafos anteriores, el Acuerdo relativo se encuentra inserto en el Protocolo General de Investigación y Persecución del Delito y, pueden destacarse los siguientes aspectos:

Se hace una clasificación primaria considerando la naturaleza dolosa o culposa de los delitos, como lo establece el artículo 202 del CNPP, y de ahí se hacen otras subclasificaciones que integran diversas variables que se desarrollan en cinco incisos: 
a) En el primero, el acuerdo se ocupa del caso de los delitos culposos y establece tres variables: en la primera, reiterando el principio establecido en el precepto señalado del CNPP, determina que cuando el acusado no haya sido previamente condenado por delito doloso y la pena señala al delito de que se trate no exceda del término medio aritmético de 5 años, solicitará la reducción de hasta un tercio de la pena mínima, cuando se trate de un delito calificado como grave por el Código Penal o bien, que se reducirá hasta en dos tercios la pena, si el delito por el que se le acusa no está determinado como grave en el ley penal.

En la segunda variable, se prevé que, en el caso de delitos graves, cuando el acusado colabora con información eficaz para la persecución y condena de otros integrantes de la delincuencia, se le otorgará la reducción de la mitad de la pena.

En la tercera variable, el acuerdo señala que en los demás casos la reducción no podrá ser menor a un sexto de la pena. Sin embargo, es difícil establecer cuáles serían los demás casos a que se refiere esta variable, porque ya todos están comprendidos en la primera y su excepción en la segunda. Es decir, ya están comprendidos todos los delitos culposos calificados o no como graves por la ley penal.

b) En el segundo inciso, el acuerdo regula el tema de los delitos dolosos en dos apartados. En el primero, reiterando la regla general establecida en el CNPP relativa a que, si el acusado no ha sido condenado previamente por delito doloso y el término medio aritmético de la pena relativa al delito que se le atribuye no excede de cinco años, se reducirá la pena mínima hasta en un cuarto, cuando se trate de delitos que afecten los siguientes bienes jurídicos protegidos:

- la vida,

- la salud,

- el normal desarrollo psicosexual,

- la libertad y la seguridad personal,

- el libre desarrollo sexual,

- la sana convivencia familiar,

- la dignidad de las personas,

- la función administrativa, la procuración o impartición de justicia;

Luego establece que se reducirá hasta en un tercio de la pena mínima correspondiente en el caso de delitos que atenten contra el patrimonio y el buen despacho del servicio público o la hacienda pública.

Y el segundo apartado dispone que fuera de los casos anteriores, se solicitará la reducción de hasta la mitad de la pena mínima.

c) En el tercer inciso, el acuerdo dispone que, en caso de no actualizarse los casos establecidos en el inciso previo, las reglas para la reducción de la pena mínima serán las siguientes:

Hasta un octavo, cuando se afecte el bien jurídico tutelado consistente en:

- la vida,

- la salud,

- el normal desarrollo psicosexual,

- la libertad y la seguridad personal, 
- el libre desarrollo sexual,

- la función administrativa, la procuración o impartición de justicia.

Hasta un sexto, cuando se lesionen los siguientes bienes protegidos:

- la sana convivencia familiar,

- la dignidad de las personas,

- la seguridad personal,

- el buen despacho del servicio público o la hacienda pública.

Y que fuera de los supuestos determinados en las fracciones antecedentes, se pedirá la reducción de hasta un tercio.

d) En el cuarto inciso, el Acuerdo determina que, dentro de los rangos de punibilidad establecidos en los incisos previos, se tomarán en cuenta: la gravedad de la conducta típica y antijurídica, el grado de culpabilidad y los usos y costumbres cuando el imputado forme parte de un grupo étnico o pueblo indígena, es decir, emulando el Acuerdo de la Fiscalía General de la República (antes Procuraduría General de la República), adopta los elementos establecidos en el artículo 410 de CNPP, que son los criterios que el órgano jurisdiccional debe considerar para la individualización judicial de la pena.

e) Y en el quinto inciso, el acuerdo establece otras reglas para graduar el quántum la reducción de las penas y consisten en:

- Que se concederá menor reducción si el imputado fue condenado previamente por delito doloso en cualquier fuero o, si el delito por el que se formula acusación amerita prisión preventiva oficiosa.

- Que se concederá mayor reducción si el imputado aportó información para evitar la comisión de otro delito o la investigación de otros imputados o delitos.

- Que se otorgará mayor reducción, si el procedimiento se apertura con más cercanía al dictado del auto de vinculación a proceso, o menor reducción, si lo fue con mayor cercanía al auto de apertura a juicio.

Y finalmente, el Acuerdo dispone que será requisito de procedencia de solicitud de apertura del procedimiento abreviado, el que se haya pagado o garantizado la reparación del daño. Es oportuno invocar un criterio emitido por el Poder Judicial de la Federación, que aun cuando es aislado, de manera expresa reivindica al Poder Judicial como titular exclusivo de la aplicación, modificación y duración de las penas:

PROCEDIMIENTO ABREVIADO. LOS ACUERDOS QUE EMITE EL FISCAL GENERAL DE LA REPÚBLICA, EN TÉRMINOS DEL ÚLTIMO PÁRRAFO DEL ARTÍCULO 202 DEL CÓDIGO NACIO. NAL DE PROCEDIMIENTOS PENALES, SON VINCULANTES PARA EL MINISTERIO PÚBLICO AL SOLICITAR LAS PENAS DENTRO DE ESA FORMA DE TERMINACIÓN ANTICIPADA DEL PROCESO PENAL ACUSATORIO, NO PARA LOS JUECES DE CONTROL, AL IMPONERLAS.

El último párrafo del precepto citado establece que el Ministerio Público, al solicitar la pena dentro de un procedimiento abreviado, deberá observar el acuerdo que al 
efecto emita el Procurador, actualmente Fiscal General; sin embargo, dicho acuerdo no constituye una determinación que obligue a su observancia a los órganos jurisdiccionales, ni les impone obligaciones de hacer o no hacer, tampoco tiene características de abstracción, impersonalidad y generalidad, sólo se trata de un acto administrativo interno que tiende a regular el funcionamiento de la actual Fiscalía General de la República, que se constriñe al actuar de las autoridades que señala el propio acuerdo. Atento a lo expuesto, el Juez de control, al imponer las penas en esa forma de terminación anticipada del proceso penal acusatorio, no debe someterse a un acuerdo general que no es vinculante para las autoridades jurisdiccionales (Suprema Corte de Justicia de la Nación, Registro: 2020132, 2019).

\section{CONCLUSIONES}

A) La terminación anticipada del procedimiento penal, es un derecho humano que permite el acceso efectivo y pronto a la justicia en el Sistema Jurídico Mexicano, está previsto en la CPEM y regulada por el CNPP y por diversos acuerdos emitidos por los titulares de las Fiscalías General de la República y de los Estados de la Federación. Es una de las innovaciones del sistema de enjuiciamiento penal vigente.

B) El sistema penal mexicano, dentro de la trayectoria de la CPEM, ha transitado por tres principios o propósitos esenciales: regeneración (1917-1965), readaptación social (1965-2008) y reinserción social (2008 a la fecha), pero las penas desproporcionadas, las modernas formas de delincuencia, la corrupción y la impunidad, hacen altamente cuestionable su funcionamiento, su eficacia y sus resultados.

C) Dentro del sistema de administración de justicia penal, de acuerdo con los párrafos primero y segundo del artículo 21 de la CPEM, corresponde al Ministerio Público la investigación de los delitos y el ejercicio de la acción penal ante los tribunales y con base en el párrafo tercero, la imposición de las penas, su modificación y duración, deben de ser propias y exclusivas de la autoridad judicial.

D) En el caso de satisfacerse los requisitos constitucionales y legales para la apertura del procedimiento abreviado, el acusado será beneficiado con la imposición judicial de la pena mínima que corresponda al delito por el que se le encausó la que, de acuerdo con el artículo 202 del CNPP es susceptible de reducirse a petición del propio órgano acusador. El CNPP establece los lineamientos para que ello opere y, además determina que los titulares de los órganos de procuración de justicia deben expedir un Acuerdo que reglamente esa atribución, pero ésta atenta contra el derecho humano constitucional de acceso a la justicia y el relativo a que la imposición, modificación y duración de las penas, es una facultad propia y exclusiva de la autoridad judicial. El Ministerio Público, en ambos fueros, hoy en día es una institución altamente cuestionable en cuanto a su eficacia, eficiencia y resultados a la sociedad por los graves índices de corrupción e impunidad, resultando incomprensible que el legislador le haya dejado una herramienta procesal tan delicada, que en sus manos se convierte en un riesgo procesal de alta consideración y desde luego limita e impide el acceso a la justicia. Debe corregirse ese desatino en el CNPP a través de una reforma urgente, que devuelva al Poder Judicial el monopolio 
integral de la imposición, modificación y duración de las penas, e incluso, al tratarse de un ejercicio de justicia negociada, quede en la propia ley procesal tasado el monto de la reducción de la pena mínima, como se establecía en su momento el artículo 389 párrafo cuarto Código de Procedimientos Penales para el Estado de México abrogado (СРPEM) por el CNPP, que establecía que en el caso del procedimiento abreviado, se impondría al acusado la pena mínima reducida en un tercio y con ello se da certeza plena a los actores del procedimiento penal, principalmente al acusado y la sociedad en general.

E) Los dos acuerdos - Fiscalía General de la República y Fiscalía General de Justicia del Estado de México-, son cuestionables porque entrañan múltiples requisitos y variables que deben combinarse para que el Ministerio Público pueda establecer el monto de la reducción de la pena mínima que solicite al órgano jurisdiccional se imponga al acusado que se haga beneficiario de un procedimiento abreviado, lo que resulta inadecuado para una correcta fijación del quántum de la reducción de la pena mínima. Lo que termina por convertir a esta potestad en una atribución altamente compleja, de difícil concretización y que hace que el Ministerio Público, en uso de una facultad que no les es constitucionalmente propia, limite o haga nugatorio el acceso a la justicia por parte del acusado en un procedimiento penal.

F) Aunque se entiende el propósito de los párrafos tercero y cuarto del artículo 202 del CNPP, de dar al Ministerio Público la potestad de autorizar la reducción de las penas mínimas que imponga la autoridad judicial, su redacción es defectuosa porque se utiliza en ambos párrafos la expresión podrá solicitar la reducción... y ello podría, en un criterio muy limitado, hacer pensar que esa solicitud es de su potestad, pero que hará el pedimento al órgano jurisdiccional y éste decidirá si disminuye o no las sanciones; igual criterio de redacción se aplicó en los Acuerdos que han sido objeto de revisión, sin embargo, no hay duda de que, en esta materia, el CNPP determina que en el caso del procedimiento abreviado, se impondrá la pena mínima que corresponda al delito por el que se formuló acusación, la que podrá reducirse a solicitud del Ministerio Público, en las proporciones señaladas.

\section{REFERENCIAS}

1. Acuerdo A/035/2018 por el que se establecen los lineamientos para la implementación de medios alternativos de solución de controversias en los juicios y procedimientos en materia penal de la Procuraduría General de la República. Diario Oficial de la Federación, México, 9 de mayo de 2018.

2. Acuerdo número 06/2016 del Procurador General de Justicia del Estado de México, por el que se autoriza el Protocolo General de Investigación y Persecución del Delito. Periódico Oficial, Gaceta del Gobierno del Estado de México, 18 de mayo de 2016 y Fe de Erratas del Acuerdo del Procurador General de Justicia del Estado de México, por el que se autoriza el Protocolo General de Investigación y Persecución del Delito, publicado en el Periódico Oficial, Gaceta del Gobierno, 18 de mayo de 2016. 
3. Acuerdo A/017/2015 por el que se establecen los criterios generales y el procedimiento que deberán observar los agentes del Ministerio Público de la Federación, para solicitar la pena en el procedimiento abreviado. Diario Oficial de la Federación, México, 23 de febrero de 2015.

4. Código Nacional de Procedimientos Penales. Diario Oficial de la Federación, México, 5 de marzo de 2014.

5. Código de Procedimientos Penales para el Estado de México, publicado en la Gaceta de Gobierno del Estado de México el 9 de febrero de 2009 y abrogado a partir de la entrada en vigor del Código Nacional de Procedimientos Penales en el Estado de México, según declaratoria de inicio de vigencia, publicada la Gaceta del Gobierno del Estado de México, el 21 de enero de 2015.

6. Código Penal para el Estado de México, Gaceta del Gobierno del Estado de México, el 20 de marzo de 2000.

7. Comisión Nacional de los Derechos Humanos (2019). Derechos Humanos de las Personas en Reclusión Penitenciaria, Marco normativo nacional e internacional del sistema penitenciario. México: $\mathrm{CNDH}$, material electrónico para Cursos en línea.

8. Constitución Política de los Estados Unidos Mexicanos (CPEUM). Diario Oficial de la Federación, México, 5 de febrero de 1917 y sus reformas.

9. El Procedimiento Abreviado en el Sistema de Justicia Penal Acusatorio (2017). Boletín Interprocuradurías, Conferencia Nacional de Procuración de Justicia. Nueva Época. Publicación Informativa número 47 de la Conferencia Nacional de Procuración de Justicia, enero-junio 2017.

10. De los lineamientos por los que se establecen los criterios generales y el procedimiento para la aplicación de criterios de oportunidad y de la determinación de la pena que el ministerio público solicitará al juez de control en la aplicación del procedimiento abreviado, publicados en cumplimiento al acuerdo CNPJ/XXXIII/12/2015, adoptado en el marco de la XXXIII Asamblea Plenaria de la Conferencia Nacional de Procuración de Justicia. Diario Oficial de la Federación, México, 9 de febrero de 2016.

11. Informe de Justificación del 28 de noviembre de 2017, rendido por el Titular de la Unidad de Transparencia de la Fiscalía General de Justicia del Estado de México, mediante oficio 1378/MAIP/FGJ/2017, dentro del trámite del Recurso de revisión 02591/INFOEM/IP/RR/2017, relacionado con la solicitud de información pública 00540/FGJ/IP/2017. Instituto de Transparencia, Acceso a la Información Pública y Protección de Datos Personales del Estado de México y Municipios.

12. Ley Nacional de Ejecución Penal. Diario Oficial de la Federación, México,16 de junio de 2016. 
13. Lineamientos por los que se establecen los criterios generales y el procedimiento para la aplicación de criterios de oportunidad y de la determinación de la pena que el Ministerio Público solicitará al juez de control en la aplicación del procedimiento abreviado. Secretaría Técnica de la Conferencia Nacional de Procuradores. Normateca de la Procuraduría General de la República. 2015. Vigentes. www.pgr.gob.mx, https://aplicaciones. pgr.gob.mx/normatecasustantiva/Paginas/Normateca-Sustantiva.aspx\#.

14. Naime, A. y Zaragoza, L. (2019). El principio de igualdad en el Procedimiento Abreviado. Revista Derecho y Cambio Social (58) octubre-diciembre, 2019. Perú. pp. 360-385. Recuperado de https://nx.derechoycambiosocial.com/ojs3.1.14/index.php/derechoycambiosocial/article/ view/258/147.

15. Pereznieto, L. (ed.) (2019). Código Nacional de Procedimientos Penales. Poder Judicial del Estado de México. México: Tirant Lo Blanch.

16. Solicitud de información pública 00540/FGJ/IP/2017. Instituto de Transparencia, Acceso a la Información Pública y Protección de Datos Personales del Estado de México y Municipios. 